\title{
CHALLENGES BEFORE AND AFTER DETECTING PLAGIARISM
}

\author{
Angelos Rodafinos ${ }^{1}$, Liza Warwick ${ }^{2}$, Diane Robbie ${ }^{2}$ \\ ${ }^{1}$ Monash University (AUSTRALIA) \\ ${ }^{2}$ Swinburne Online (AUSTRALIA)
}

\begin{abstract}
Cheating and plagiarism are possibly the major academic offences. In the past, plagiarism detection systems have been inefficient and University policies underdeveloped or lacking rigour in addressing these issues. Strong integrity policies and efficient processes for dealing with plagiarism are required to assure quality, and promote and maintain academic integrity within Universities. However, it appears that even to this day, not all Universities are using plagiarism detection systems, and that only a portion of them have developed and are indeed enforcing the policies. Students who plagiarise pose two challenges. A first challenge is when the student is not caught. Surprisingly, as we demonstrate, a second challenge arises when a student is caught. This paper presents some of the challenges academia faces in detecting, examining and determining an outcome, reporting, and recording plagiarism cases. We offer recommendations on how academics and administration can address the challenges that follow the identification of an incident, with a particular focus on the last two phases. Incidents can only be processed effortlessly and efficiently when systems are well designed, and the process is carefully mapped and structured. We then outline the steps and present guidelines on how the process can be streamlined efficiently. Flowcharts and decision trees assist the decision makers, while checks and ticks and automated controls can improve consistency among staff. Further debate is required to discuss the necessity of national or indeed international registries to record incidences of academic dishonesty.
\end{abstract}

Keywords: integrity, ethics, processes and systems.

\section{INTRODUCTION}

Academic misconduct encompasses a broad spectrum from cheating on examinations, fabricating results, colluding, and duplicating ideas, words and work without appropriate acknowledgement [1], [2], [3]. Plagiarism, the unacknowledged use of another author's work or ideas, is perhaps one of the more difficult academic offences to address. A small scale literature review using Rapid Evidence Assessment (REA) was undertaken to examine the existing research in this area. The REA methodology streamlines a traditional research review in limiting the search process by date and database [4], thereby reducing time and resource constraints. A subsequent Google Scholar search for "plagiarism" resulted in a response of 283,000 articles, with 20,300 articles published in 2015 alone.

The majority of studies in plagiarism have focused on student, academic and institutional attitudes towards plagiarism [5], [6], [7], [8], [9], reasons why and how students plagiarise [2], [3], [6], [10], who and what segments of the student population plagiarise [1], [11], cultural influences on plagiarism [12], [13], understanding and awareness of academic writing conventions, academic integrity and knowledge of institutional policies [1], [14], [15], views on plagiarism deterrence and detection [16], current policies and systems attempting to address plagiarism, or the lack of these [17], [18], [19], [20], institutional characteristics for learning, study and assessment in promoting academic integrity and minimising plagiarism incidents [1], [6], [18], and plagiarism in the digital age [21], [22]. However, as Glendinning [23] has pointed out, little attention has been given to examining the effectiveness of policies and processes in addressing plagiarism and subsequently very few responses were returned for the search terms "effectiveness of plagiarism policies and procedures."

Inaction and silence to plagiarism are at the heart of academic dishonesty [2], [24]. We need to ask what we wish our Universities to be known and remembered for, and what calibre of students we wish our Universities to graduate. Administrators should strive to embed academic scholarship across all facets of university life instilling a culture that values academic integrity above all else [3], [18]. Academic integrity needs to lie at the very foundation of scholarly practice, a responsibility of academic staff, administrators and students alike [18].

In this paper we present some of the challenges academics face in detecting, reporting, and recording plagiarism, with a particular focus on the last two phases, using several examples to illustrate the 
importance of these issues. Finally, we offer suggestions on how academics and institutions can attempt to address the challenges that follow the identification of an incident.

\subsection{To Check or not to Check? A Dual Challenge}

Students who plagiarise by presenting someone else's work or ideas as their own, pose a dual challenge. The first challenge is when the student is not caught. Surprisingly, as we will demonstrate, the second challenge emerges when a student is caught.

Let us consider the first challenge. Students who plagiarise and are not caught present two serious issues, one for academics and academia and one with even broader consequences for society in general. A University's credibility is measured, among other variables, by the calibre of the students and professionals it produces. Graduating students who have systematically plagiarised but have not been detected affect - or should affect - the University's reputation, research funding, and ranking. The University is liable to the taxpayers and society, and should safeguard the quality of education it provides and the graduates it produces, because the second issue, the consequences at the broader, societal level may be quite severe.

Students who receive degrees and grades they do not deserve can become incompetent professionals: lawyers, doctors, teachers, and lecturers. Lawyers who do not know the law, doctors who cannot diagnose or operate, teachers who are unsuitable to teach, and academics unable to produce original research and knowledge. For some of these imposters, poor academic practice or overt and intentional plagiarism during their studies may result in small glitches throughout their professional work, for example, lack of expertise in the classroom, or to more serious issues, such as, adverse health effects or even the death of their patients. Hence, there really should be no dilemma whether to check for plagiarism or not. Check? Yes, please!

Until recently, plagiarism detection systems have been inefficient and University policies underdeveloped or lacking rigour [23], [25], [26]. Public groups have formed aiming to identify professionals who received degrees and acquired positions they did not deserve. Using wiki technology such as VroniPlag and GuttenPlag and crowdsourcing, these groups have uncovered and revealed similarities in the work of prominent scientists, managers, and politicians. In a number of fraud cases, Universities had to retract degrees, resulting in the professional and personal humiliation and occasional resignation of the plagiarists, many years after they committed the offence. These associations also disseminate information and compare anti-plagiarism software tools amongst their members and the academic community. Related sources and forces against plagiarism include web sites such as plagiarism.org, which presents information on plagiarism and its prevention, retractionwatch.com, which publicises cases of academic fraud, and the commercial turnitin.com, which, among other resources, has developed a list of internet services that promote the sale or sharing of written work.

Moving forward, to reduce the frequency of such incidents, rather than relying on post-incident discoveries by independent groups or individuals, Higher Education Institutions (HEIs), need to instil a culture of academic integrity and accountability in both academics and students alike. This requires investing in the prevention and detection of plagiarism to ensure the high ideals of good scholarship academia value continue to form the foundation of our learning environments. As many scholars have outlined previously, a holistic institutional approach from education, intervention to prevention is necessary [1], [2], [3], [11], [18]. Figure 1 below is based on the model of prevention and intervention to address health issues [27] and illustrates the arenas where education, intervention, and prevention of plagiarism can take place. The graphic suggests an overall response to ensure not only high standards of academic integrity within the student population but ongoing ethical standards for the professionals they will become.

The second major challenge for academics arises when the instructor detects that there is something wrong with the student's work and wonders how to go about reporting it. The next sections discuss recommendations for prevention, policies, and procedures to deal with plagiarism cases. 


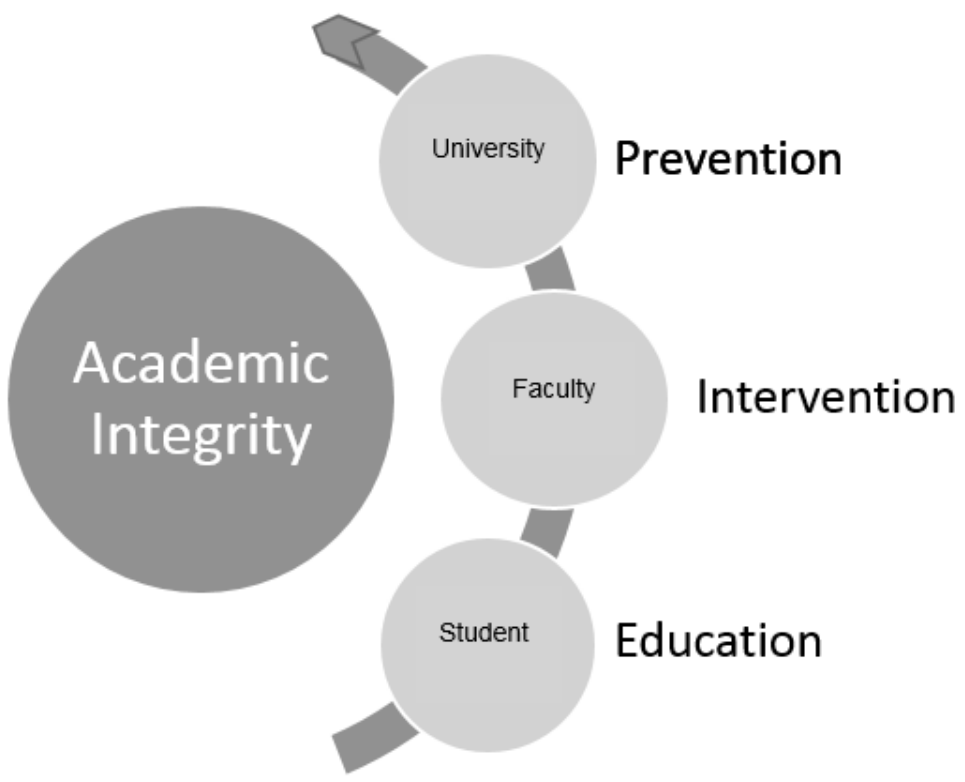

Fig. 1. Arenas for Promotion of Academic Integrity and Scholarship.

\section{DEALING WITH PLAGIARISM}

\subsection{Prevention}

Previous research examining student academic integrity awareness, why students cheat, and who cheats has led to a better understanding and provided useful information for the encouragement of good scholarship and the prevention of plagiarism [1], [2], [3], [18], [28], [29]. As with many prevention and intervention programs and models, the best approach is training on academic writing and referencing skills, education on academic integrity and what constitutes plagiarism, and the wrongfulness of engaging in it.

Much can be done in terms of educating students and training tutors. In terms of methods, options include embedding tutorials on scholarship and academic integrity and guidelines on writing and referencing in the students' induction program, in foundation pre-study courses, or within one or several of the core or foundation units. Yet, even then, there will always be some bad apples in the bunch, which makes checking for plagiarism equally important. Fostering academic integrity requires a holistic and multi-stakeholder approach [1].

\subsection{Policies, Systems and Procedures}

Although scarce, research into strategies, systems, and procedures to promote academic integrity and address the challenges presented by plagiarism and academic misconduct does in fact reveal that many countries have developed national initiatives. Policies and processes are certainly required to promote and maintain assurances of quality, standards, and academic integrity within Universities [1], [19]. A number of HEls have established codes of conduct, policies and procedures, and offer guidelines to staff on detecting and dealing with plagiarism cases. Whether these systems are effective or not is the subject of our discussion below.

Glendinning surveyed students, teaching staff and senior managers, to determine how well institutional procedures were understood and implemented, and whether outcomes within and between institutions were consistent and aligned with policies [23]. Results indicated that $71 \%$ of all EU teachers $(N=5000)$ agreed that their institution has policies and procedures for dealing with plagiarism. Academics from certain EU countries, including Italy, Spain, France, Portugal, Belgium, Finland, Bulgaria, and Germany were much less confident (25-100\% of respondents disagreed). Senior management respondents 
(70\%) expressed doubt about the consistency of approach to penalties for students. According to the author, it appears that systemic failures are common, and review and reforms of policies across all levels of higher education governance are required. Glendinning concluded that "HEls in many parts of Europe had poorly defined policies and systems for assurance of academic integrity. In some countries and institutions where policies were in place, there was little evidence of monitoring and review" (p.17).

Hence, it appears that not all HEls have developed policies, systems and processes for dealing with plagiarism, and that only a portion of them are indeed enforcing these. Obstacles in implementation include considerations regarding issues such as a) the seriousness of such accusations and the consequent implications for the student's degree and career, b) the dangers of possible litigation by the accused students against the University, and c) the reputation of a University that reports large numbers of such cases.

We believe that two additional operational factors, which have not yet received the required attention, impede the reporting of plagiarism incidents. These are the complexity and subjectivity of decision making once plagiarism has been detected, and the amount of administrative work involved. Discussions with a number of colleagues supported our contention that instructors often opt out from carefully checking student papers or think twice before reporting such incidents, unless their University has adopted a) plagiarism detection software b) an official policy requiring the examination of all student papers, c) clear guidelines on decision making, and d) an easy to follow process for reporting plagiarism. It also appears that recording and subsequent monitoring of plagiarism incidents is lacking, and as a result, students' second offences are often treated as initial ones, damaging the credibility of many Universities.

\subsection{The Process: Steps in Dealing with Plagiarism}

To illustrate the complexity of the process and the workload involved, consider the following scenario. Assume that 200 of your students have submitted their work. According to the reports generated by the plagiarism detection software that your University uses, $10 \%$ of them have minor or major issues in referencing. You are now required to make 20 important decisions, which for inter-rater reliability purposes should be consistent to those of your colleagues. Each case and each decision involves the following stages: a) detection and selection of cases with high similarity, b) careful examination of the evidence (e.g., comparison of the script and the sources), including contacting students or colleagues for further information if needed, c) completion of a report form, d) decision, which may require consultation with other parties (e.g., unit convenor, chair, authorised officer, administration), e) communication of the decision to involved parties, and f) recording on student records (see Fig. 2).

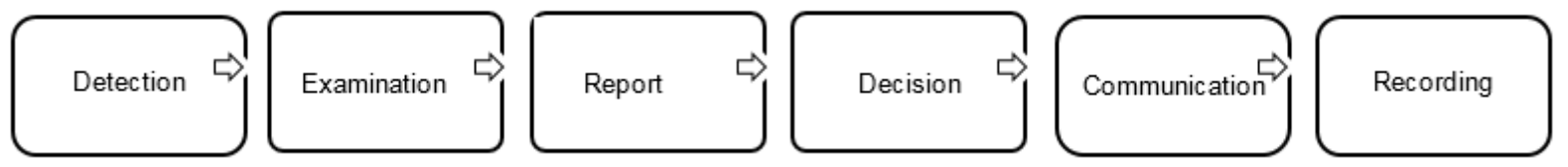

Fig. 2. Steps in Dealing with Plagiarism

Incidents can be processed effortlessly and efficiently only when the whole process is carefully mapped and structured. Flowcharts and decision trees can assist the decision makers, while automated checks can improve consistency among staff. The following section delineates the above steps and presents some recommendations on how to efficiently streamline the process.

\subsubsection{Step 1. Detection}

As already alluded, only in the past couple of decades have academics been able to use sophisticated and relatively accurate software to confirm their suspicions about a submitted assignment. These programs compare a student's work with past submissions or other online sources. Commercial web sites include Turnitin, at a cost of a couple of dollars for institutional subscriptions, and SafeAssign, which is free for institutions with Blackboard enterprise accounts. Free plagiarism check sites or software include DupliChecker, PaperRater, PlagiarismChecker, Plagiarism-detect, Viper and many others. Gipp has developed a Citation-based Detection System (CbDS) that uses citation patterns rather than text comparisons to detect heavily disguised plagiarism [30].

Such advances in technology allow us to detect the similarity of student work with internet based sources, or what Professor Geoffrey Alderman of the University of Buckingham called type-1 plagiarism [31]. However, the challenge lies in detecting type-2 plagiarism, or ghost written essays, that is, original papers that essay writing services or paper mills produce on behalf of the student, usually for a fee. In 
fact, internet based essay writing services are flourishing. How prevalent is the phenomenon? The 2015 MyMaster essay cheating scandal revealed that around 1000 students from 16 Australian universities had submitted assignments that had been paid for through these services [32]. According to the Daily Mail Online, 50,000 students have been caught cheating in exams or essays in the past three years in the UK alone [31]. A mere 1\% of them has been judged guilty of academic misconduct. In addition to that, some of the better students often report they have been approached by classmates and offered compensation to write their papers and even their doctoral dissertations.

The existing software cannot identify the original author. Further, in legal terms, submitting an assignment written by someone else may not even violate the copyright law, as the student has usually purchased the rights. It does, however, violate academic integrity regulations, as the author is presenting someone else's ideas as their own, and deceives the lecturer and the academic community. According to Professor John Simons, Macquarie Deputy Vice-Chancellor, Universities are working to resolve these issues. For instance, the University of Melbourne is trialling Cadmus, an online tool that analyses students' keystrokes to stop cheats [33]. Once again, it appears that addressing these cases will require a coordinated, holistic and multi-stakeholder approach.

\subsubsection{Step 2. Examination of the Evidence: How much is too much?}

Alas, all existing plagiarism detection software packages are merely tools - useful, but still tools, which require training in their use (e.g., adjusting the settings on text recognition, exclusion of quotes or references) and in the interpretation of the similarity reports they produce. Originality reports help instructors identify the text within the submitted papers that is highly similar to other sources (e.g., student papers, articles, online material). Yet, there are no clear guidelines in terms of the amount or percentage of similarity that justifies further examination and action. In fact, this has been the cause of much frustration, particularly for new academics. The first author's rule of thumb suggests "Any idea or text that is not your own should be referenced. If not, it is plagiarism."

A high percentage of similarity is always a good starting point, but as no system is perfect, a manual check is always required. Instructors should carefully examine and drill down into the report to check for similarities between the paper and the sources, review the parts that have been highlighted, exclude quoted material, commonly used phrases, references etc. and compare these to the original sources. Often, the instructor may need to request permission from another university's instructor to access a copy of the source material. At other times, for example, when it is not obvious who copied from whom, an informal investigation and communication with the students involved may be required.

Curtin University has collated a number of clues in the student's work, which, when examined, may suggest the possibility of plagiarism or contract cheating [34]. These include:

"few or no in-text citations; references or direct quotes; unusual formatting or discontinuities in formatting style; mixed spelling (American vs Australian) or terminology; inconsistencies in language style (introduction and conclusion inconsistent with the body of the assignment); different styles used for intext citations and references, bibliographies with two or more styles; no up-to-date references, citations of foreign authors only; out-dated information, references to past events as if they were current; going off the topic; differences in expression and style throughout the paper; failure to localise sources appropriate to the assessment or inclusion of non-local source material (e.g., in an assignment focusing on Australian tax law, with unexpected reference to tax laws from other countries where this was not required)" (p. 14).

\subsubsection{Step 3. Report}

Once the required information has been collected, the instructor needs to submit a report to the Academic Department and/or to the Registrar. The report should include details about the student, the unit, the assessment, the amount of similarity, dates, and past history, if any, as well as free text comments.

One would hope that at most HEls, emails have replaced the traditional paper reports. More advanced systems use web forms or tailor-made software. By automatically pre-filling certain fields, such online forms can accelerate the process and significantly reduce the effort required. For instance, entering the student ID number can bring up the students' record, units studied during the current period, past history/incidents, pre-fill the date etc.

What is even more useful, when designed carefully, these systems can guide the instructor with a simple decision tree that incorporates the institution's policy, the related definitions, and guidelines how to 
proceed, all in one place. The instructor can follow the branches, select among options and tick the related boxes recommending a penalty and a course of action. Once completed, the report and the instructor's recommendation can be automatically shared, communicated and submitted to other parties (e.g., Department Chair, Authorised officer, Registrar) before it is communicated to the student, as described in Step 6 below.

\subsubsection{Step 4. Decision Making}

The first decision that the instructor has to make is the level of the incident. Policies in most HEls distinguish between poor academic writing and plagiarism. The former is due to lack of knowledge or skills, while the latter is usually characterised by intention. As expected, most of the times, this distinction is not clear. Hence universities offer guidelines and provide criteria to assist staff in the classification of incidents. The most prominent one is the amount of similarity to other sources. As previously indicated, a high match does not necessarily warrant plagiarism. For instance, the student may have used an excessive amount of quotations and cited or referenced the sources. Similarly, a low similarity report does not necessarily preclude or exclude plagiarism. For example, a student may have copied a single large paragraph or section and presented it as their own, without providing a citation. Once again, the instructor needs to clarify that this was not accidental, for example, the student did not just copy the material from notes and forgot to add the related reference.

Other factors that need to be considered during decision making include the level of the student, whether it is a first or a repeat offence, whether it appears to be intentional, etc. Obviously, more experienced students who have completed several units may not be allowed to plead ignorance and claim poor academic writing practice, provided of course that the university has offered guidelines and some feedback/training. On the other hand, in cases where the student has submitted someone else's work or a paid essay, academic misconduct is justified independent of the level of the student.

Poor academic writing normally does not carry penalties. Rather, the aim is to educate the student and encourage academic integrity. For this purpose, options usually include educational advice and requests to study links and readings on writing and referencing, requests to revise and resubmit, an informal warning, or a small reduction in marks.

As the degree of seriousness of the plagiarism offence increases, so do the sanctions. For example, students may be asked to attend counselling or a lecture, seminar, workshop or similar activity; repeat assessment with reduced maximum mark; receive a reduced or nil grade in respect of the assessable item in which the academic misconduct occurred; an annulled due to academic misconduct result for the unit or for other units in the same teaching period; suspension of student's rights for a short or longer period; exclusion from attendance; denial of access to facilities or services; exclusion; termination from the course; expulsion from the university; and rescission or withholding of any award [34].

\subsubsection{Procedure}

At the first stage, for poor academic practices or minor offences, instructors have to complete forms with the required information (preferably online) and suggest an initial recommendation. A notification is sent to the head tutor or unit convenor (preferably automatically). For efficiency, when making their recommendation, tutors should be able to click and select from a number of options and suggested courses of action for each level of plagiarism (preferably via the use of drop down menus).

For low level cases, instructors should be able to make a decision and determine the sanction or penalty. However, in the case of more serious offences, due to the potentially severe implications for the student as well as the HEl in case of appeals, there is a strong need to ensure that each decision is accurate and well justified. Issues of concern include incorrect classifications and false accusations. False positives refer to instances when a student's work is wrongly identified as plagiarism. Obviously, the reverse can happen too; students' copied work is not always picked or identified as such. However, as Carrol suggested rather than looking for evidence "beyond all reasonable doubt" the standard of proof should be "on balance of probability" [26].

Inter-rater reliability, fairness and consistency among instructors within the same or different courses, departments, faculties or universities is another matter of concern. Safeguards can include referrals and checks by more experienced lecturers or dedicated academic integrity staff. To ensure consistency and reduce errors, senior members of staff (e.g., the Chair or the Authorised Officer) should overview all cases, determine or approve the final decision, decide on sanctions or recommend the case to a discipline Committee. Again, automated systems and templates can accelerate and make the process more efficient. 


\subsubsection{Step 5. Communication}

Once a final decision has been made, someone has to communicate it to the student in the most appropriate way. A professional and firm, yet polite and respectful, official letter should be sent to the student. Due to the seriousness of the situation, templates for each level of offence should include a) a description of the problem and the nature of the offence, b) links to university policies and educational resources, c) the outcome, and d) the process in case the student wishes to appeal. Again, ideally, the data that the instructor entered in the first stage should feed into the template letter and be sent with the click of a button to all parties involved.

\subsubsection{Step 6. Recording}

To record or not to record? The answer, has again, to be yes. If incidents are not recorded on the student's file, another instructor will treat the next occurrence as a first time offence. In fact, this is probably the most undeveloped area in the whole process. Some instructors rely on their memory, others maintain their own records, while occasionally emails are circulated to check whether other colleagues within the same department have had any issue with a particular student. Additionally, it is important for the instructor to make an informed initial decision based on their own judgement without and preconceived biases about a student. However, the student's previous history on plagiarism should be considered. Once again, record keeping can be arduous, unless automated systems are used. An issue of concern with plagiarism records is who has access to sensitive personal information. Confidentiality requirements present a challenge as such data should be handled and stored appropriately and should not be accessible to all staff.

\section{CONCLUSION}

Academic misconduct is an offence and due to the proportions of plagiarism, one of the bigger challenges in academia. To plagiarise or not to plagiarise? The answer ought to be a resounding "no". Unfortunately, the bad apples will continue their "work," assisted by other bad apples, and by the lack of checks, regulations and water-tight processes. Studies in social psychology and behavioural economics (see for example Ariely [35]) have indicated that education, social norms, and legislation may help to prevent and reduce cheating.

Current policies, detection, decision processes, and reporting of incidents vary among HEls. In addition, recording systems are scarce and the efficiency of processes used is questionable. We do not see any reason why policies, processes and punishments should differ among institutions, in the same or different countries. The same laws apply for different organisations within the same city, state, or country, and occasionally internationally as well. Similarly, despite arguments for confidentiality, we do not see the reason why a national registry cannot be created, at least for high level offences, much like criminal records. Online degrees and student mobility, which are projected to increase, will allow students to enrol in units from different HEls. Unless a common registry is established, recording plagiarism incidents will become an even more difficult task than it currently is. A registry will ensure those caught plagiarising cannot simply change courses or Universities until they find one with relaxed policies or ineffective systems, and receive a degree they do not deserve. Having said that, the emphasis should be on prevention rather than discipline, although there is no doubt that the latter does certainly reinforce the former, much like traffic fines reinforce speed limits.

\section{REFERENCES}

[1] Bretag, T. (2013). Challenges in addressing plagiarism in education. PLoS Medicine 10(12), pp. $1-4$.

[2] Park, C. (2004). Rebels without a clause: towards and institutional framework for dealing with plagiarism by students. Journal of Further and Higher Education 28(3), pp. 291-306.

[3] Park, C. (2003). In other (people's) words: plagiarism by university students - literature and lessons. Assessment and Evaluation in Higher Education 28(5), pp. 471-488.

[4] Ganann, R., Ciliska, D., \& Thomas, H. (2010). Expediting systematic reviews: Methods and implications of rapid reviews. Implementation Science 5(56), pp. 1-10.

[5] Jager, K., \& Brown, C. (2010). The tangled web: Investigating academics' views of plagiarism at the University of Cape Town. Studies in Higher Education 35(5), pp. 513-528. 
[6] McCabe, D.L. (2005). Cheating amongst college students: A North American perspective. International Journal for Educational Integrity 1(1), pp.1-11.

[7] Tennant, P., \& Duggan, F. (2008). Academic misconduct benchmarking research project: Part 2. The recorded incidence of student plagiarism and the penalties applied. UK: Higher Education Academy. Retrieved from http://www.plagiarismadvice.org/resources/institutionalapproaches/item/tennant-amber2

[8] Tennant, P., \& Rowell, G. (2010). Benchmark plagiarism tariff for the application of penalties for student plagiarism and the penalties applied. UK: The Higher Education Academy. Retrieved from http://www.plagiarismadvice.org/resources/institutional-approaches/item/tennantreferencetariff

[9] Wilkinson, J. (2009). Staff and student perceptions of plagiarism and cheating. International Journal of Teaching and Learning in Higher Education 20(2), 98-105.

[10] Klein, D. (2011). Why learners choose plagiarism: A review of literature. Interdisciplinary Journal of E-Learning and Learning Objects 7, pp. 97-100.

[11] Scanlon, C.L. (2006). Strategies to promote a climate of academic integrity and minimize student cheating and plagiarism. Journal of Allied Health 35(3), pp. 179-185.

[12] Hayes, N., \& Introna, L.D. (2005). Cultural values, plagiarism, and fairness: When plagiarism gets in the way of learning. Ethics \& Behaviour 15(3), pp. 213-231.

[13] Stappenbelt, B., Rowles, C., \& May, E. (2009). Cultural influence on attitudes to plagiarism. In teaching and learning for global graduates. Proceedings of the 18th Annual Teaching Learning Forum, 29-30 January 2009. Perth: Curtin University of Technology. Retrieved from http://otl.curtin.edu.au/tlf/tlf2009/refereed/stappenbelt.html

[14] Gullifer, J.M., \& Tyson, G.A. (2014). Who has read the policy on plagiarism? Unpacking students' understanding of plagiarism. Studies in Higher Education 39(7), pp.1202-1218.

[15] Power, L.G. (2009). University students' perceptions of plagiarism. Journal of Higher Education 80(6), pp. 643-662.

[16] Decoo, W., \& Colpaert, J. (2010). Detection systems for text-based plagiarism: Developments, principles, challenges, and the aftermath. Writing \& Pedagogy 2(2), pp. 311-320.

[17] Kaktiņš, L. (2014). Appraising plagiarism policies of Australian universities. Text \& Talk 34(2), pp. 117-141.

[18] Macdonald, R., \& Carroll, J. (2006). Plagiarism: A complex issue requiring a holistic institutional approach. Assessment and Evaluation in Higher Education 31(2), pp. 233-245.

[19] Morris, E. J., \& Carroll, J. (2015). Developing a sustainable holistic institutional approach: Dealing with realities 'on the ground' when implementing an academic integrity policy. In Bretag, T. (Ed.), Handbook of academic integrity, pp. 1-11. Singapore: Springer.

[20] Weber-Wulff, D. (2014). False Feathers. A Perspective on Academic Plagiarism. Springer.

[21] Broussard, L., \& Hurst, H. (2015). Plagiarism prevention and detection. Nurse Educator 40(4), pp. 168.

[22] Nilsson, L. (2016). Technology as a double-edged sword: A promise yet to be fulfilled or a vehicle for cheating? In Bretag, T. (Ed.), Handbook of academic integrity, pp. 607-624. Singapore: Springer.

[23] Glendinning, I. (2014). Responses to student plagiarism in higher education across Europe. International Journal for Educational Integrity 10(1), pp. 4-20.

[24] Joob, B., \& Wiwanitkit, V. (2014). Letter to the editor: Medical school, research misconduct policies, and procedures. Accountability in Research 21(6), pp. 401-402.

[25] Foltýnek, T., \& Glendinning, I. (2015). Impact of policies for plagiarism in Higher Education across Europe: Results of the project. Acta Universitatis Agriculturae Et Silviculturae Mendelianae Brunensis 63(1), pp. 207-216.

[26] Carroll, J. (2007). A handbook for deterring plagiarism in higher education (2nd Ed.). Oxford: Oxford Centre for Staff and Learning Development. 
[27] Mrazek, P. B., Haggerty, R. J., Institute of Medicine (U.S.), \& United States. (1994). Reducing risks for mental disorders: Frontiers for preventive intervention research. Washington, DC: National Academy Press.

[28] Fisher, D., \& Frey, N. (2013). Plagiarism: Prevention through teaching. IRA E-ssentials, pp.1-8.

[29] Sims, R.L. (2002). The effectiveness of a plagiarism prevention policy: A longitudinal study of student views. Teaching Business Ethics 6(4). pp. 477-482.

[30] Gipp, B. (2013). Citation-based plagiarism detection: Detecting disguised and cross-language plagiarism, using citation pattern analysis. USA: Springer.

[31] Daily Mail Online. (2016, January 2). Cheating students pose university challenge. Retrieved from http://www.dailymail.co.uk/wires/pa/article-3381637/Cheating-students-pose-universitychallenge.html\#ixzz3x00bVy40

[32] Visentin, L. (2015, May 28). Macquarie University revokes degrees for students caught buying essays in MyMaster cheating racket. Retrieved from

http://www.smh.com.au/national/education/macquarie-university-revokes-degrees-for-studentscaught-buying-essays-in-mymaster-cheating-racket-20150527-ghba3z.html

[33] Wells, J. (2016, April 18). UniMelb trials keystroke detection system to stop cheats. Campus Review. Retrieved from http://www.campusreview.com.au/2016/04/unimelb-trials-keystrokedetection-system-to-stop-cheats/

[34] Curtin University. (2015). Academic integrity at Curtin: Staff guidelines for dealing with student plagiarism. Retrieved from http://academicintegrity.curtin.edu.au/local/docs/StaffPlagiarismGuide.pdf

[35] Ariely, D. (2012). The (honest) truth about dishonesty: How we lie to everyone--especially ourselves. New York: Harper. 